\title{
Bottlenecks blocking widespread usage of planning support systems
}

\section{Guido Vonk}

Copernicus Institute for Sustainable Development and Innovation, Utrecht University,

PO Box 80115, 3508 TC Utrecht, The Netherlands; e-mail: g.vonk@geo.uu.nl

\section{Stan Geertman}

Urban and Regional Research Center Utrecht, Utrecht University, PO Box 80115, 3508 TC

Uretcht, The Netherlands; e-mail: s.geertman@geo.uu.nl

\section{Paul Schot}

Copernicus Institute for Sustainable Development and Innovation, Utrecht University, PO Box 80115, 3508 TC Utrecht, The Netherlands; e-mail: p.schot@geo.uu.nl

Received 15 January 2004; in revised form 25 May 2004

\begin{abstract}
Research on planning support systems (PSS) is characterized by a strong emphasis on the supply side, whereas little research has been undertaken on the successes and failures in the adoption of PSS within the planning community (demand side). What becomes clear from the existing research is that usage is not widespread. In this paper we aim to find the main bottlenecks blocking the widespread use of PSS in spatial planning. To achieve this, a global online survey was conducted in which almost 100 PSS experts participated and for which a theoretical framework from the field of business studies served as a basis. The results show that a multitude of factors cause the underutilization of PSS, their characteristics being human, organizational and institutional, as well as technical. In particular, the lack of awareness of and experience with PSS, alongside the relative lack of recognition of the value of PSS within the spatial planning community, tend to block widespread usage and adoption of PSS in planning practice. On this basis, we offer recommendations for the enhancement of PSS adoption, namely to disseminate more profoundly information and knowledge about the existence and benefits of PSS within the spatial planning community. Real-world example projects and in-depth research on potential benefits of PSS application in planning practice will be crucial in this.
\end{abstract}

\section{Introduction}

An assessment of spatial planning practice at the end of the 20th century suggested that the adoption and use of geoinformation tools (geographic information and spatial modeling systems) are far from widespread and far from being effectively integrated into the planning process (Stillwell et al, 1999). From the assessment it may be concluded that many planners now have access to the geodata and meta-geoinformation facilities of their organizations, and many are proficient in using their geoinformation tools to perform spatial queries and to generate thematic maps. Progress towards the use of these tools beyond these basic activities to help solve key planning problems through more sophisticated analysis, however, remains very limited (Stillwell et al, 1999). Geoinformation tools appear to be seldom used for those tasks that are unique to planning, such as visioning, storytelling, forecasting, analysis, sketching, and evaluation (Couclelis, 2003; Klosterman, 1997).

Studies to explain the shortfall in the adoption of geoinformation tools have often taken a broad, systems-analytical perspective, suggesting not only reasons of a technical nature, but also human, organizational, and institutional factors. Alleged reasons are that most current tools are far too generic, complex, and inflexible, incompatible with most planning tasks, oriented towards technology rather than problems, and too focused on strict rationality (Batty, 2003; Bishop, 1998; Couclelis, 1989; Geertman 
and Stillwell, 2003a; Harris and Batty, 1993; Innes and Simpson, 1993; Klosterman and Landis, 1988; Nedovic-Budic, 1998; Scholten and Stillwell, 1990; Sheppard et al, 1999; Sieber, 2000; Uran and Janssen, 2003).

Quite recently, a new generation of geoinformation tools has entered the scene that is focusing directly on support of spatial planning tasks, the so-called planning support systems (PSS). As a precursor, Harris (1989) defined PSS as appropriate models for combining a range of computer-based methods and models into an integrated system that can support the spatial planning function. PSS bring together the functionalities of geographic information systems (GIS), models, and visualization, to gather, structure, analyze, and communicate information in planning. Or, as recently defined by Geertman and Stillwell (2003b), PSS can be considered a subset of geoinformationbased instruments that incorporate a suite of components (theories, data, information, knowledge, methods, tools, etc) that collectively support all of, or some part of, a unique planning task. In this way, PSS take the form of 'information frameworks' that integrate the full range of information technologies useful for supporting the specific planning context for which they are designed (Geertman and Stillwell, 2003c; Klosterman, 1997). Tools like GIS and spatial decision support systems (SDSS) are related to PSS and some overlap exists. In general, however, PSS aim to focus purely on planning support, whereas many SDSS and GIS technologies can be used for planning support if required, but are not particularly dedicated to that use [for more information on general differences between PSS, GIS, and SDSS see Geertman and Stillwell (2003b)].

Over the last few years, individuals or groups based at scientific, research, or planning institutions around the world have been involved in the development, testing, and implementation of a range of PSS (Batty and Densham, 1996; Bishop, 1998; Dijst et al, 2003; Edamura and Tsuchida, 1999; EPA, 2000; Guhathakurta, 2002; Hopkins, 1999; Klosterman, 2001; Landis, 2001; Omer, 2003; Snyder, 2004; TCDDM-V, 2003; URISA, 2003; Voss et al, 2003; Waddell, 2002; Wegener, 2001). Several authors have attempted to create a comprehensive picture of the extent of planning support tools that constitute PSS. This effort resulted in two books, among others: one that concentrates on the different aspects related to PSS (Brail and Klosterman, 2001); the other showing the immense diversity of PSS by presenting the outcomes of a worldwide survey of PSS in planning practice (Geertman and Stillwell, 2003b).

Besides these two more or less supply-side-oriented contributions, there remains little insight into the demand for PSS in planning practice. This absence of insight is remarkable because one can conclude that the widespread adoption and implementation of PSS in planning practice are dragging far behind the supply of PSS tools. This underusage is problematic at a time when spatial planning is increasingly complex and planners are showing an increasing demand for support (Bishop, 1998; Geertman and Stillwell, 2003d; Voss et al, 2003).

A review of the scarce literature on the application of PSS in planning practice reveals some hints as to the reasons for the shortfall. First, the literature confirms the aforementioned reasons for underusage of geoinformation tools in general. However, hardly any studies provide general insights into bottlenecks for the specific field of PSS. A decade ago, Harris and Batty (1993) concluded that the lack of existing PSS leads planners to be ignorant of their potential, causing a lack of demand. A few years later, Bishop (1998) concluded that existing tools are too loosely coupled for them to constitute a PSS. Recently, Geertman and Stillwell (2003c) stated that a great diversity of PSS has been developed, but that there is a serious need for a more explicit focus on the planning and support aspects of PSS instead of - as is often the case-on their system aspect. They provide a series of recommendations, based on interpreted bottlenecks from a series of cases. 
A more thorough overview of empirical bottlenecks does not yet exist. The deficit in demand for PSS therefore cannot be fully explained with reference to existing knowledge. Our primary aim in this paper is to shed more light on the reasons for this underutilization. We do this by explicitly questioning developers and users about which bottlenecks may be preventing widespread usage of PSS in planning practice. Insights from this investigation may help developers of PSS to attune their tools better to the demands of planning practice, and at the same time it may help potential users of PSS - the planners - to formulate their requirements more explicitly. By advancing our knowledge in this way, we hope to stimulate the application of PSS in planning practice and improve the handling of practical planning problems.

\section{Theoretical framework}

We regard the adoption and implementation of PSS as a special case of adoption and implementation of any information and communication technology (ICT) system. In this way, we can make use of extensive lines of research on adoption and implementation of ICT from the theoretical domains of innovation science, management science, and business studies (Davis, 1986; Dishaw and Strong, 1999; Frambach and Schillewaert, 2002; Mathieson, 1991; Rogers, 1962; 2003; Thompson et al, 1991; Venkatesh and Davis, 2000; Wilson et al, 2002). Innovation-science research on technology adoption and implementation has evolved largely around Rogers's famous work Diffusion of Innovations (Rogers, 1962; 2003), in which technology adoption and implementation are considered at both an organizational and an individual level. The core of this research line is a model consisting of five sequential stages in innovation adoption and implementation: (1) generation of awareness of existence of an innovation; (2) persuasion and the formation of an attitude towards the innovation; (3) an adoption decision; (4) implementation; and (5) confirmation.

In management science, research on technology adoption and implementation originates from a basic theory in social psychology: the theory of reasoned action (Fishbein and Ajzen, 1975). This became a landmark research line when the paper "Technology acceptance model" by Davis was published in 1986. This model has been verified over a hundred times since and was updated and extended by Venkatesh and Davis in 2000. Technology acceptance is considered here only at an individual level. Its main components are the attitude towards an innovation, leading to acceptance of the innovation, and continued usage of the innovation. This attitude is formed by two central factors, 'perceived usefulness' and 'perceived ease of use', which are influenced by a number of external factors such as the 'output quality' and 'job relevance' of the innovation.

As both lines of research can to some extent be considered two sides of the same coin, quite recently Frambach and Schillewaert (2002) integrated the two in a comprehensive multilevel framework. This integrated framework, which was published in the field of business studies, has been used as a basis for the study presented in this paper. A version, showing only influence factors at an aggregated level, is shown in figure 1 (see over).

Figure 1 shows that an organization-level decision to adopt an innovation that may lead to continued use is preceded first of all by generation of awareness, after which potential users may start to consider using an innovation and from this they form an intention to use it. These factors are directly influenced by the 'adopter characteristics' for example, organization size), organizational 'environmental influences' (for example, competitiveness) and the 'perceived innovation characteristics' (for example, perceived complexity); and are indirectly influenced by 'social network' characteristics (for example, network participation), 'provider marketing efforts', and also the organizational 'environmental influences'. Following the organizational-level adoption decision, the 


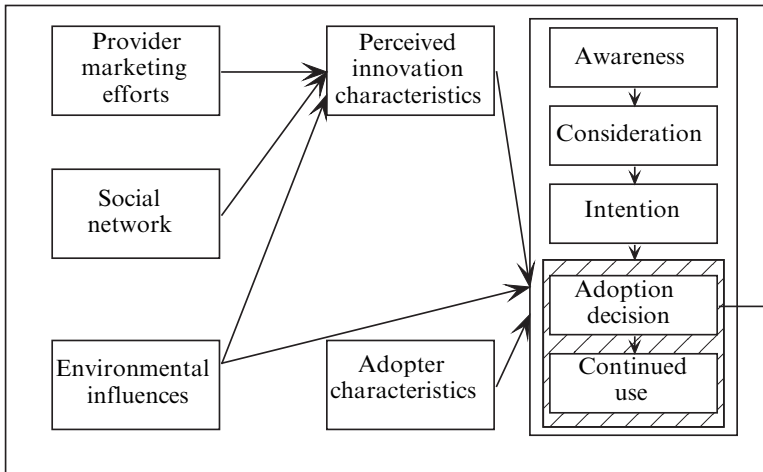

Organization level

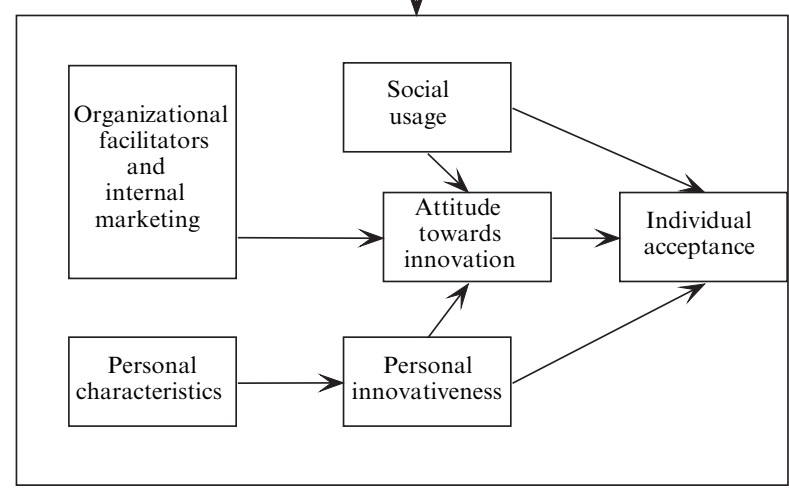

Individual level

Figure 1. Framework for innovation adoption (after Frambach and Schillewaert, 2002).

innovation will only actually be used if the individuals within the organization adopt the innovation. Within the context of an organization, acceptance and usage at the individual level are influenced directly by 'attitude towards an innovation', 'social usage' characteristics (such as social pressure) and 'personal innovativeness'; and indirectly by 'organizational facilitators and internal marketing' (for example, training), 'personal innovativeness' (depending on personal characteristics), and 'social usage' (for example, persuasion by colleagues) (Frambach and Schillewaert, 2002).

The main advantage of this framework lies in the combination of major organizational and individual factors determining innovation adoption in one systematic framework. It enables one to undertake research on adoption of an innovation as a whole, instead of focusing on particular aspects, as in many other studies (Karahanna and Straub, 1999; Schmitz and Fulk, 1991). Nonetheless, the framework also has some severe limitations when applied to PSS. First, the applicability is limited to top-down technology adoption and implementation. This implies that first an adoption decision is taken at an organizational level, and only thereafter do the employees of the organization decide whether or not to start making use of the innovation. In our perspective, successful adoption and implementation can start at both the individual and the organizational level. For instance, in a bottom-up acceptance (individual level), a planning professional finds out about a system, evaluates its usefulness and, usually with managers' consent, he or she will start using it. The second limitation, linked to the first, is that the framework suggests that the characteristics of a technology are relevant only at an organizational level and not at the end-users' level. It assumes that end-users do not judge a system on its capabilities. This seems to contradict Venkatesh 
and Davis's (2000) model, in which they consider 'output quality' and 'job fit' as important determinants of individual technology acceptance. Moreover, it contradicts our experience with end-users. Third, the framework presented focuses on information technology in general and not on PSS in particular. Some refinement is required because, after all, PSS are not the same as word processors or spreadsheet programs.

Because of these limitations, we undertook some modifications on the Frambach and Schillewaert framework, in line with mentioned shortcomings. Pure top-down technology adoption and implementation is replaced by a mutual top-down and bottom-up process. Moreover, some factors were added which were considered to be missing at one of the two adoption levels, for instance, 'awareness', 'consideration', and 'perceived innovation characteristics' at the individual level and 'social influence' among managers on the organizational level. In addition, the third limitation required some further research of the literature on PSS, as well as related technologies such as GIS and SDSS, and expert judgment from colleagues. Several factors considered important for explaining PSS adoption and implementation were found in Croswell in his (1991) paper on GIS-adoption, and in books on PSS by Brail and Klosterman (2001) and by Geertman and Stillwell (2003b). As a result, extra factors were added to our framework, for instance, factors concerning 'hardware issues' and 'data issues'. Finally, the framework was somewhat simplified for visualization purposes. Figure 2 shows the adapted framework. In this adapted version, the upper dotted boxes within different factors correspond largely with the organizational-level boxes in figure 1, the lower with individual-level boxes. The inclusion of both levels in the framework enabled us to study adoption of PSS from a broad perspective, in agreement with our expectations that adoption of PSS may start at the individual and the organizational level.

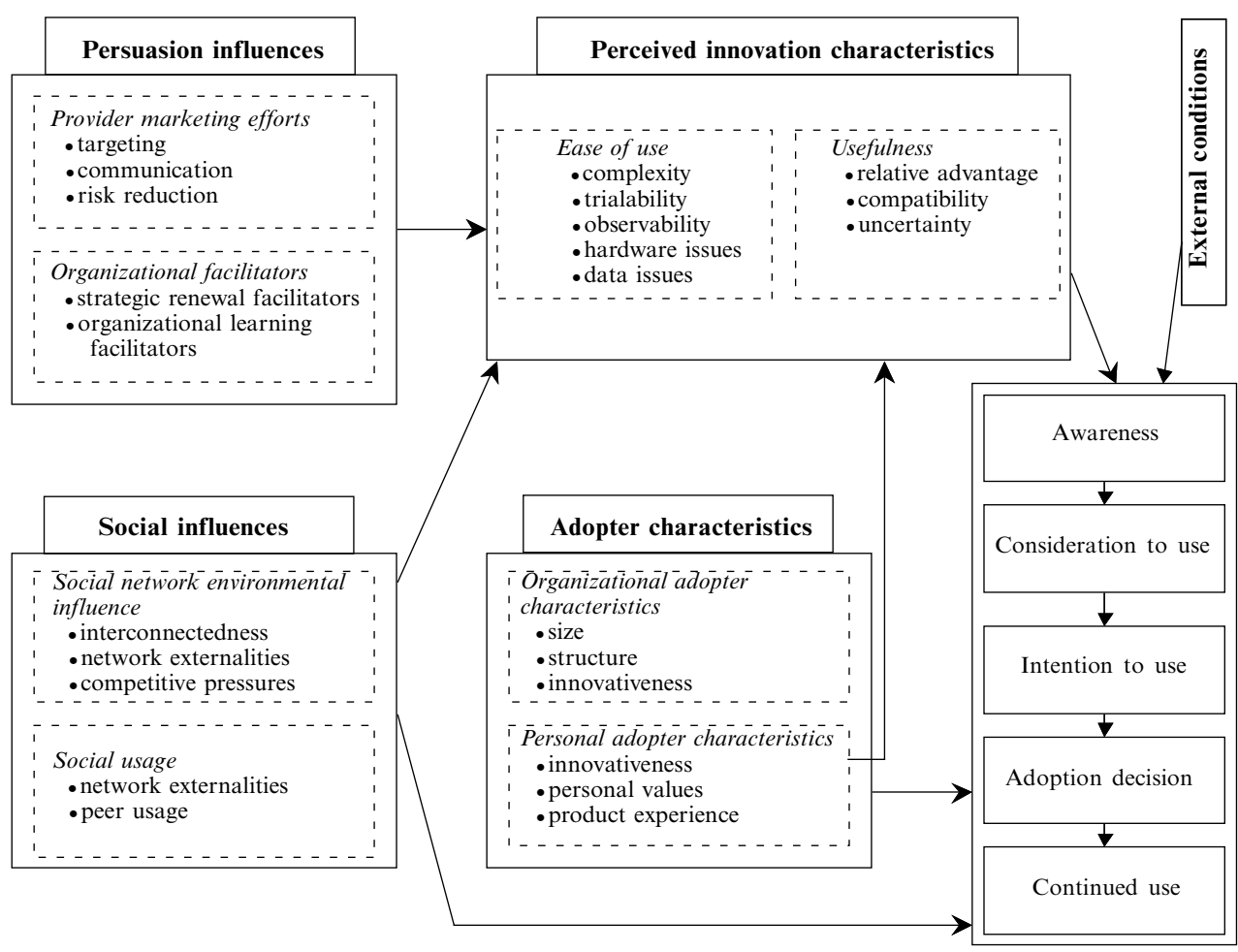

Figure 2. Theoretical framework for this research project. 
We conducted a survey to determine the importance of the influence factors in explaining why the use of PSS for spatial planning is not widespread; influence factors were converted to bottleneck indicators, the importance of which was measured with bottleneck statements.

\section{Method}

Using the theoretical framework, we constructed a web survey to discover empirically the main bottlenecks preventing the more widespread use of PSS in spatial planning practice. In March 2003, via several electronic and regular mailing lists, approximately 800 people involved in PSS around the world were asked to participate in the survey by filling out our online form.

The main part of the questionnaire consisted of sixty-seven statements, referring to potential bottlenecks, of which the importance had to be judged. These statements were based on technology adoption studies in information systems literature and in geoinformation literature (Brail and Klosterman, 2001; Croswell, 1991; Davis, 1989; Dishaw and Strong, 1999; Geertman and Stillwell, 2003b; Karahanna and Straub, 1999; Masser and Onsrud, 1993; Rogers, 2003; Uran and Janssen, 2003; Venkatesh and Davis, 2000). For each statement, respondents could distinguish between one of four categories: 'unimportant', 'important', 'very important', and 'don't know'. For evaluation of the received enquiries, questions were added to determine the characteristics of the survey population, such as their origin, working position, affiliation to PSS, and experience with PSS. In particular, the experience of the respondents was considered crucial to the value of their replies; their experience was determined by asking respondents to select from a list of thirty-four well-known and less well-known PSS, those they had worked with or heard about. The list consisted of a selection of planning tools described in an Environmental Protection Agency (EPA) study and two PSS overviews (Brail and Klosterman, 2001; EPA, 2000; Geertman and Stillwell, 2003b). In addition to the closed statements and questions, open questions were provided to suggest additional bottlenecks that were not on our list and to add comments about bottlenecks.

First, during the analysis, PSS experts were distinguished from nonexperts, according to the criterion that experts should have at least heard of, or worked with, two out of the thirty-four listed PSS.

Second, the indicated importance of each of the bottleneck statements was calculated by combining the frequency scores of the answer categories 'important' and 'very important'. For interpretation, these combined scores were compared with frequency scores for the answer categories 'unimportant' and 'don't know' to determine how unanimous respondents were in their judgments on the importance of the statements.

Third, the sixty-seven bottleneck statements were classified into twenty-four bottleneck indicators, to increase transparency and consistency. Consistency was particularly important because many statements were close in meaning or even partially overlapping. The average frequency score of contributing statements reflects the importance of a bottleneck indicator. Consistency of the indicators was evaluated by using distributions of frequency scores of contributing statements.

Fourth, results were validated, by analyzing and comparing the results from subgroups of respondents with the results from all respondents. Small differences in results indicate unanimity among respondents, which contributes to the general validity of the results, whereas larger differences indicate the opposite. Subgroups were distinguished on the basis of geographical origin and expertise. With regards to geographical origin, subgroups were made consisting of Europeans and North Americans, as these were the only subgroups large enough for analysis. With regard to expertise, subgroups were made consisting of 'moderate experts' - those knowing more than one but fewer than ten PSS - and 'greater experts' - those knowing more than ten PSS. 
Fifth, the bottleneck indicators were interpreted in relation to the theoretical framework, thus providing insight into how the important bottleneck indicators are interrelated and how they affect adoption and implementation. To this end, the bottleneck indicators were grouped, as far as possible, into the different factors distinguished in the theoretical framework. The average frequency score per group of bottlenecks was calculated and represents the factor score. From this measure it is possible to derive the relative importance of the different factors in the theoretical framework.

Finally, the rankings of important bottleneck indicators, and their interrelations and effects on adoption and implementation, were used to develop an overall interpretation of bottlenecks that prevent more widespread usage of PSS.

\section{Results}

\subsection{Bottleneck indicators}

\subsubsection{Exploration of responses}

In total ninety-six respondents filled out the form, which is estimated as approximately a $12 \%$ response ratio. Figure 3 indicates the level of PSS knowledge of the ninety-six respondents. It shows that $90 \%$ of respondents (eighty-six) had heard of or worked with at least two of the systems, and this group was therefore included in the category experts in further analysis. The other $10 \%$ (ten respondents) were excluded. In general, respondents' knowledge of PSS seems to be quite high, as $50 \%$ of respondents had heard of or worked with more than six systems. One respondent claimed to know all of the thirty-four listed PSS. Moreover, the analysis of respondents' PSS knowledge also revealed that 'UrbanSim' $(56 \%)$ was the best-known system, followed by 'What If?' (44\%) and 'CommunityViz' (mim (41\%) (Klosterman, 2001; Kwartler and Bernard, 2001; Waddell, 2002).

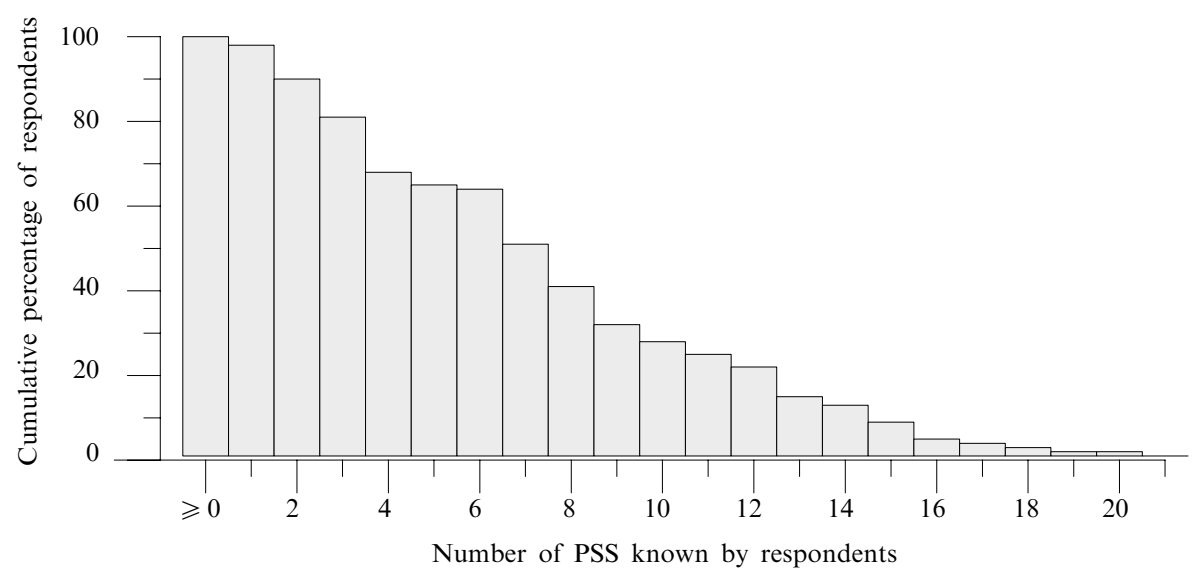

Figure 3. Cumulative frequency of PSS knowledge of respondents.

Figure 4 (see over) shows that most of these eighty-six respondents originate from Europe (55\%) and North America (32\%), and that most of them work at universities (49\%). Furthermore, although not shown in figure 4, most of them consider their affiliation with PSS to be as consultants or researchers $(55 \%)$ and only a few as users or developers.

\subsubsection{Analyzing bottleneck indicators}

Figure 5 (over) shows the bottleneck indicators with their importance scores (frequency of 'important' plus 'very important') derived from classification of the sixty-seven bottleneck statements into twenty-four indicators. It shows that a wide range of bottleneck indicators 


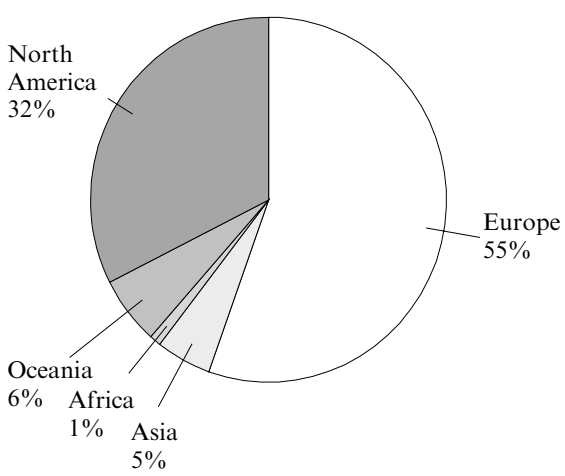

(a)

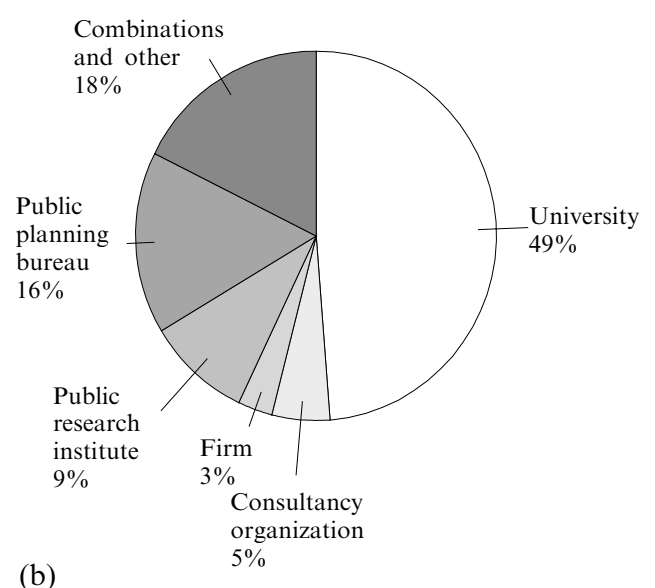

(b)

Figure 4. (a) Origin of respondents and (b) their work organization.

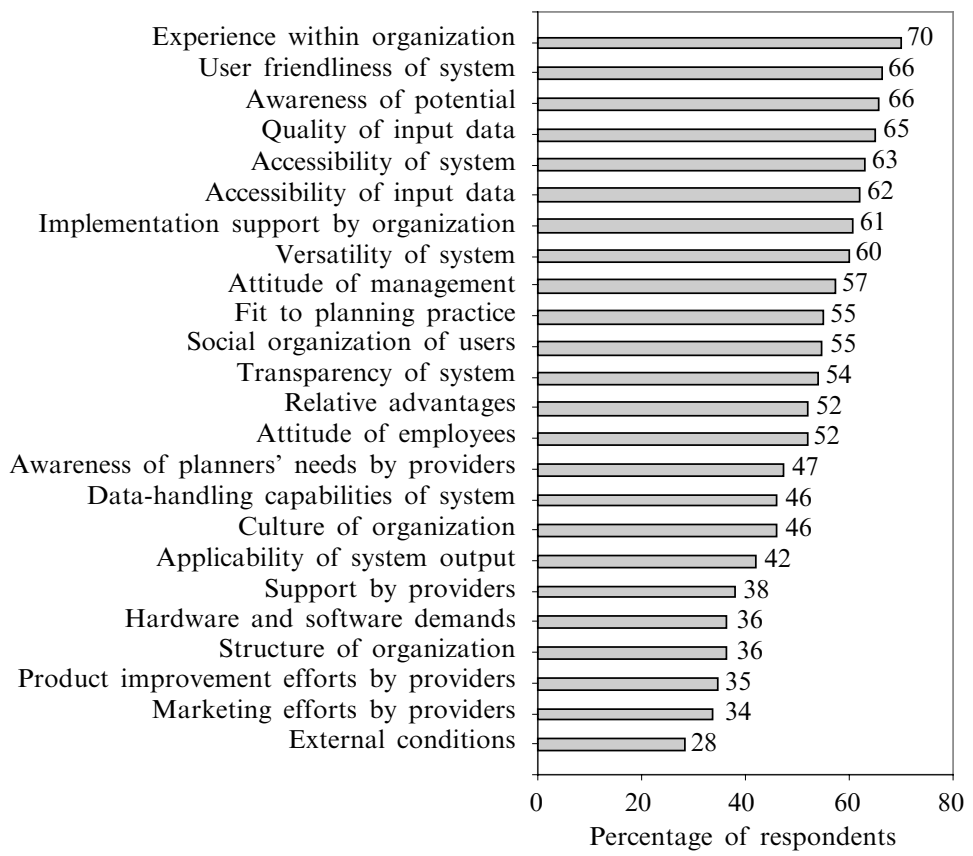

Figure 5. Bottleneck indicators with their importance.

is considered to be important. Illustrative in this respect is that the lowest scoring indicator on importance ('external conditions') is still thought to be important by $28 \%$ of respondents. We will shortly describe the ten highest scoring indicators. The three most important bottleneck indicators are 'experience within the planning organization', 'user friendliness of system' and users' awareness of potential of PSS. The importance of awareness and experience confirms the present supply-side orientation in PSS development. Besides these three most important indicators, data issues are also seen as important. Both 'quality of input data' and 'accessibility of input data' are seen as insufficient and blocking widespread usage of PSS. In addition to the difficulty of accessing required data, the 'accessibility of the system' itself can be seen as problematic. Furthermore, organizations do not really seem to put enough effort into 'implementation support', which may be a result of the 


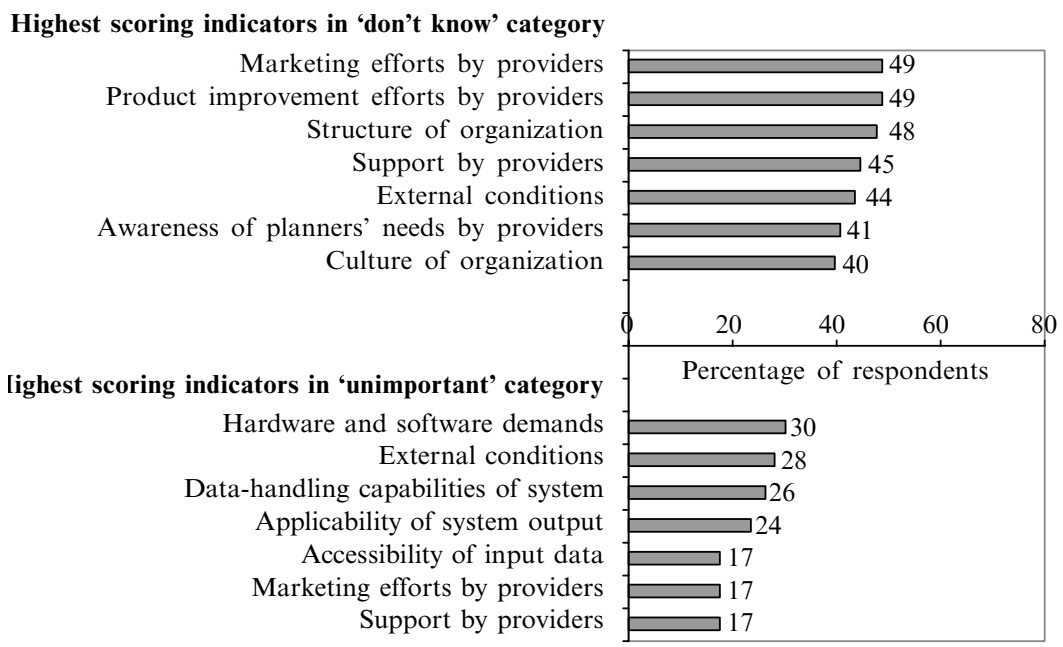

Figure 6. Highest scoring bottleneck indicators with their scores on 'don't know' and 'unimportant'.

'attitude of the management'. The PSS are also seen as neither having sufficient versatility nor sufficient 'fit to planning practice'.

Figure 6 shows the seven highest scoring indicators in the 'don't know' and 'unimportant' categories. Besides interpretation of the scores as they are, they were also used to put the previously distinguished, important bottleneck indicators in perspective. For example, an important bottleneck that also has a high score in the 'unimportant' or 'don't know' categories indicates ambiguity or doubt among respondents, which leads us to question the actual importance of the bottleneck.

The bottleneck indicators related to the role of the provider-'structure of organization', 'culture of organization', and 'external conditions'-possess high scores of between $40 \%$ and $50 \%$ in the 'don't know' category. The most unimportant indicators are quite diverse, including 'hardware and software demands', 'external conditions', 'data-handling capabilities of system', 'applicability of system output', 'accessibility of input data', and also indicators related to the role of the provider. The four highest scoring unimportant indicators distinguish themselves from the others by quite a margin. In the combined indicator 'hardware and software demands', respondent feedback indicates that hardware is judged as more unimportant than software. Although 'hardware and software demands' is the most unimportant bottleneck, the relatively low maximum score of $30 \%$ shows that little unanimity exists among respondents about the unimportant bottlenecks. Still, we see scores of $24 \%$ to $30 \%$ in the 'unimportant' category as substantial.

The fact that neither of the indicators with high scores in the 'don't know' and 'unimportant' categories is among the highest scoring indicators on importance ('important' plus 'very important') supports the value of these as important bottleneck indicators.

\subsubsection{Bottleneck indicators for subgroups of respondents}

Subgroups of respondents were analyzed to find out more about the validity of their answers. Small differences between the results for subgroups and the general results would indicate unanimity, which would contribute to the validity of the general results, whereas larger differences would indicate the opposite.

Figure 7 (see over) shows the scores of the ten indicators distinguished earlier which scored highest on importance ('important' plus 'very important') in general, 


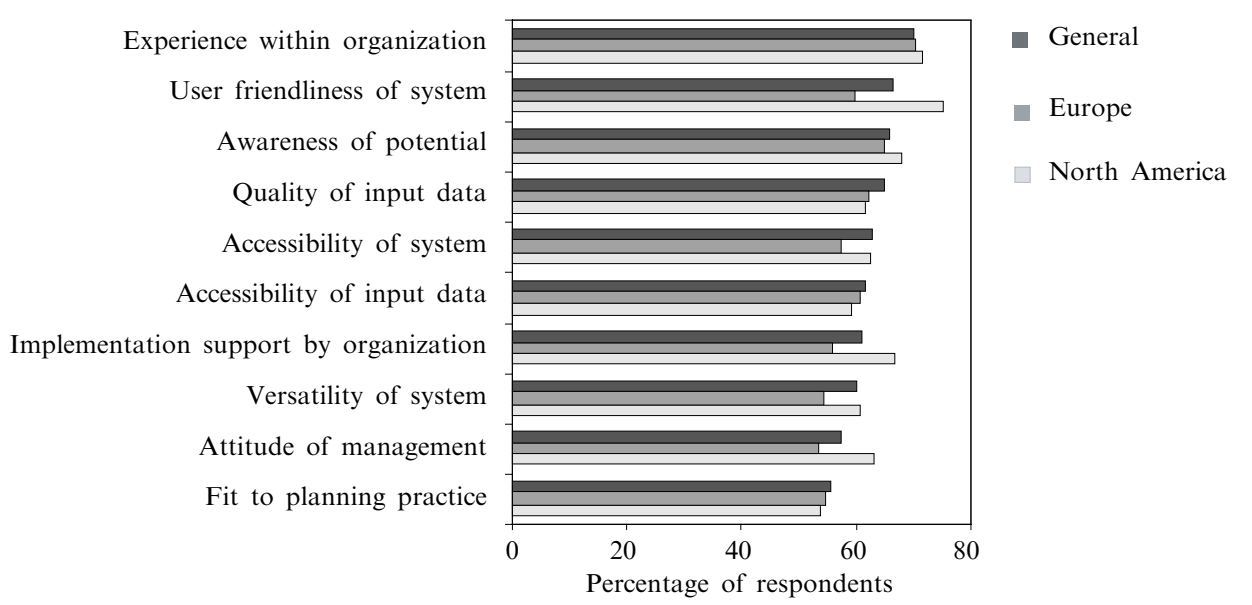

Figure 7. The ten most important bottleneck indicators for all respondents, in general, and specifically for the Europeans and the North Americans.

compared with the scores from subgroups of respondents based on geographical origin. The subgroups consisted of forty-seven Europeans and twenty-eight North Americans. In general, differences between the groups are rather small. The pattern of scores shows, however, that the respondents from North America were more outspoken than their European counterparts, with higher scores on nearly all of the shown bottleneck indicators (and also on those that are not shown here). One might explain this observation by cross-cultural differences or differences in knowledge of PSS. The correctness of these explanations was checked through analysis of the 'don't know' answers. The analysis showed little difference in knowledge of PSS between Europeans and North Americans: frequency scores show that both groups know little about the importance of approximately the same subjects and the overall frequencies of subjects responding with 'don't know' are more or less similar for both groups (35\% for Europeans, $36 \%$ for North Americans). North Americans are therefore more likely to be outspoken because of their culture and not because of superior knowledge. Besides the difference in outspokenness, both groups see approximately the same bottleneck indicators as important. A noteworthy difference is the emphasis of North Americans on 'user friendliness' as their main bottleneck indicator. Moreover, analysis showed that North Americans and Europeans also see approximately the same indicators as unimportant.

Figure 8 presents the scores of the ten indicators distinguished earlier which scored highest on importance in general, compared with the scores for subgroups of respondents based on their knowledge of PSS. The subgroups consist of sixty-one moderate experts and twenty-five greater experts. In general, differences between the groups are minimal, although there are some exceptions: it is noteworthy that the bottleneck indicator 'accessibility of input data' is seen as much more important by the group of greater experts than by the group of moderate experts. Furthermore, the greater experts have somewhat higher scores, on average, than the moderate experts, which we believe is a direct reflection of their awareness of the stated bottlenecks. Analysis showed that both expert groups see approximately the same bottlenecks as unimportant.

Results for the subgroups agreed, in general, with the results obtained earlier for all respondents for both the important and the unimportant bottleneck indicators. This contributes to the general validity of the results. 


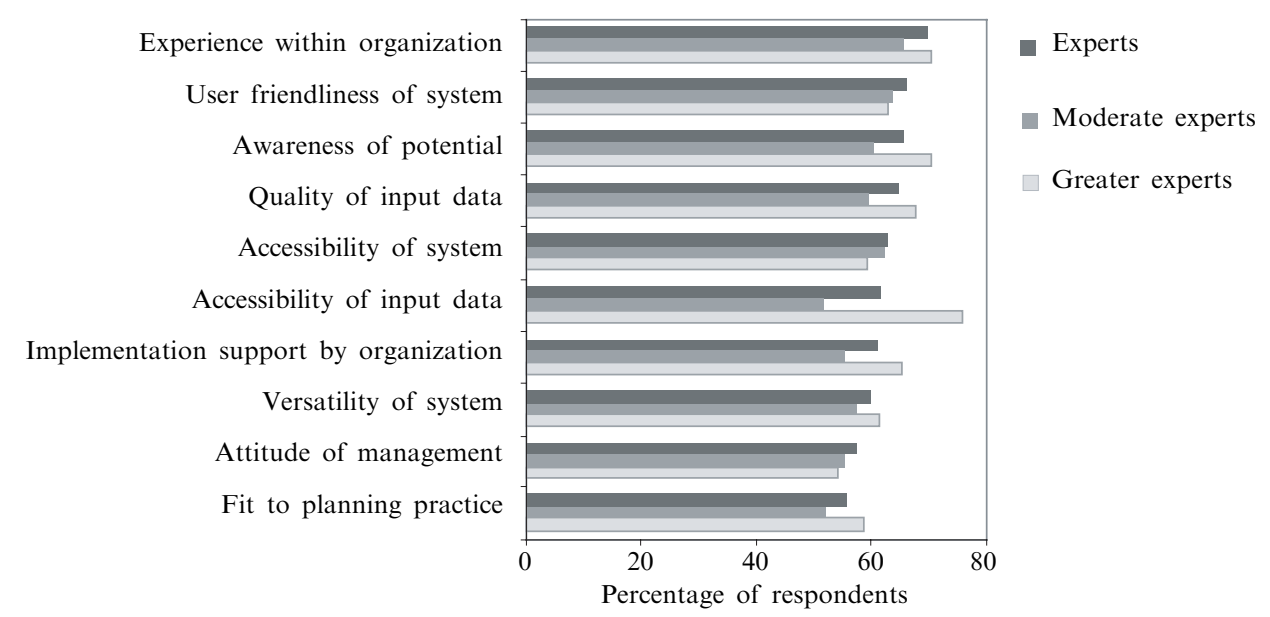

Figure 8. The ten most important bottleneck indicators for PSS experts, moderate experts, and greater experts.

\subsection{Interpretation of results}

\subsubsection{Interpretation in terms of the theoretical framework}

Just by reading the list of indicators shown in figure 5, one can see that some indicators are related. From such a list, however, these relations are not very clear. Our theoretical framework on innovation adoption helps to interpret these relations and therefore helps to add value to the results. Figure 9 (see over) shows the theoretical framework, with the bottleneck indicators and their importance scores incorporated within the suitable factors. The percentages were calculated from average frequency scores of the indicators contained within each factor and indicate the importance of the factors.

The earlier notion that there is not a single bottleneck blocking widespread usage and acceptance of PSS, but quite a diversity, is clearly conveyed by figure 9. Almost all of the factors of the theoretical framework seem to be bottlenecks. Only 'external conditions' and 'provider marketing efforts' score quite low $(<40 \%)$. The higher scoring factors range from those related to the 'organizational adopter characteristics', 'social influences', 'persuasion influences', 'perceived innovation characteristics', and 'consideration to use', which score about 40-60\%, to 'awareness', 'personal adopter characteristics', and 'organizational facilitators', which score significantly higher $(60-70 \%)$. All of these factors directly or indirectly influence the highest scoring factor, which is the 'intention to use' $(>70 \%)$. As a result of the structure of the theoretical framework, aggregation effects may well have caused the high scores of some of these factors. Because of its influential position, if 'intention to use' is a bottleneck, this more or less confirms that adoption decisions will be blocked, therefore preventing the use of PSS becoming widespread.

\subsubsection{Overall interpretation of bottlenecks preventing adoption of PSS}

The rankings of important bottleneck indicators, as shown in figure 5, and their interrelations and effects on adoption, as shown in figure 9, were used to develop an overall interpretation of bottlenecks which prevent more widespread usage of PSS. It appears that a wide diversity of bottlenecks is considered to be important. Also, there seems to be little experience with PSS among planners (indicator: 'experience within organization'). In addition to having little experience, respondents indicate that many planners are not even aware of the existence and potential of PSS (indicator: 'awareness of potential'), suggesting that the activity going on within the PSS developer community 


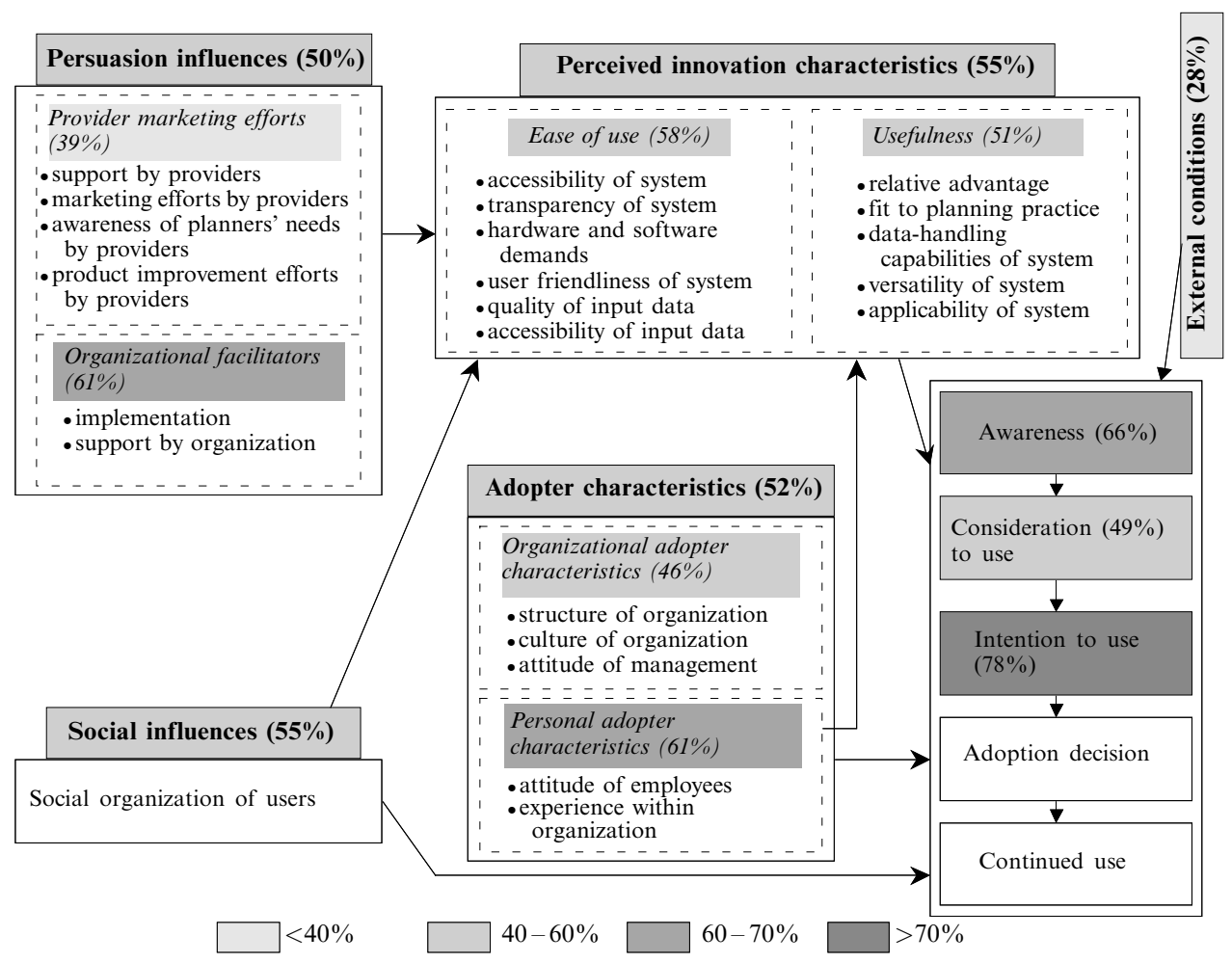

Figure 9. Bottlenecks blocking widespread usage and acceptance of PSS in terms of the theoretical framework with importance scores.

stays largely within that community. Once users have been informed about PSS they have a hard time finding them and experimenting with them (indicator: 'accessibility of system'). If users do manage to find PSS, many of them do not value them and reject the tools immediately (indicators: 'attitude of management', 'attitude of employees', 'intention to use'). This negative attitude is likely to be partially caused by the image that PSS have among planners as 'black boxes' that are difficult to operate (indicators: 'transparency of system', 'user friendliness of system'). The many years of research emphasizing the development of transparent and easy-to-use systems have clearly not changed users' perceptions a great deal. Once adopted, there are also many implementation bottlenecks to conquer before applications become a success (indicators: 'implementation support by organization', 'accessibility of input data', 'quality of input data'). The data issues are especially persistent as efforts to solve these problems have been going on for many years. Finally, the results also clearly show that the tools themselves need improving to be able to offer better support for planning tasks so that planners feel that PSS offer advantages for their work (indicators: 'fit to planning practice', 'versatility of system', 'transparency of system', 'relative advantages'). With regards to the most unimportant bottlenecks, it seems that hardware issues have been solved ('indicator: hardware and software demands'). Respondents do not have a clear idea of the role played by providers in blocking usage of PSS ('support by providers', 'marketing efforts by providers', 'awareness of planners' needs by providers', 'product improvement efforts by providers'), as these indicators scored highest in the 'don't know' category. 


\section{Methodological reflection}

Several assumptions, practices, and outcomes may have affected the results. First, no empirical verification of the theoretical framework of Frambach and Schillewaert was found in the literature. We did not consider this absence to be detrimental to the value of the results obtained, because its constituents have been verified separately in extensive lines of research dedicated to innovation adoption. As the only apparent application of the framework, this study may be also valuable for the field of business studies from which the framework was derived.

Second, because of our selection procedure based on the number of known PSS, respondents with many years of practical experience would have been excluded, if they had experience of only one system and had not heard of any other. However, we do not expect this to decrease the validity of results, because the enquiry was not established to find out the value of one particular system, but to gain insight into the broader field of PSS and its application in spatial planning practice.

Third, with respect to the respondents, there is an emphasis on the geographical hotspots of Europe and North America, on universities, and also on researchers and consultants. Although it is likely that the mailing lists are partly to blame for this emphasis, it is not expected to result in a large decrease in the broader validity of the results, because European and North American universities remain prime breeding grounds for new developments in geoinformation. Still, it must be recognized that the emphasis on university workers and researchers is important considering our aim to find out why spatial planners tend not to use PSS. The low response of planners themselves may be explained by the fact that nonusage makes it, by definition, difficult to answer the questionnaire; this is particularly indicated by the fact that a substantial mailing to planners resulted in little response. We therefore had to assume university workers and researchers are well qualified to replace the planners themselves. In general, we believe that the number of responses and the expressed knowledge on PSS form a solid basis for providing a sufficient quality of data and, thus, reliable outcomes for the further analysis of the expressed bottlenecks.

Fourth, some assumptions were made in the development of the list of statements and in classifying the statements into indicators and factors. It was assumed that: (1) the list of statements reflected the existing bottlenecks appropriately; (2) the indicators reflected the meaning of grouped statements sufficiently; and (3) the statements and indicators had weightings in the classification equal to those of the indicators and factors. Considering the absence of respondents who commented on this, and considering the sound theoretical framework used to distinguish indicators and factors, we believe that, in general, these assumptions are valid and do not decrease the value of our results.

Our findings suggest that the aim has been achieved, because we now have an overview of the main bottlenecks blocking widespread use of PSS in spatial planning. However, for particular PSS there can be numerous reasons why they would fail under particular circumstances or succeed in other settings. The bottlenecks found in this study refer to the technology as a whole, instead of referring to particular systems. The validity of the results is expected to reach beyond PSS for spatial planning only. Based on similarities between the tools themselves, processes in which the tools are applied, and current research topics in relation to these tools, we expect our results to be at least partially valid for PSS in general (Geertman and Stillwell, 2003a); GIS (Allen and Goers, 2002; Carver, 2003; De Man, 2003); SDSS (Crossland et al, 1995; Uran, 2002; Uran and Janssen, 2003); Integrated Assessment models (Hisschemöller et al, 2001; Rotmans, 1998); DSS in general (Shim et al, 2002); and Information Systems in general (Frambach and Schillewaert, 2002; Rogers, 2003; Windrum and De Berranger, 2003). 


\section{Conclusions and recommendations}

Literature suggests that the widespread adoption and implementation of PSS in planning practice is lagging behind the supply of PSS tools. The primary aim of this study has been to shed more light on the reasons for the shortfall by asking explicit questions about bottlenecks which prevent widespread usage of PSS in spatial planning practice.

The main conclusion is that there is a multitude of bottlenecks blocking widespread usage and acceptance of PSS in spatial planning practice; these can be summarized into three main categories. First, the PSS experts questioned see little awareness among planners of the existence of PSS and of the purposes for which PSS can be used. Second, they feel there is a lack of experience with PSS, which means that potential users are unaware of the benefits of using PSS and of the conditions under which PSS could best be applied. Third, they feel there is a low intention to start using PSS among possible users. These categories are probably interrelated. It is clear that, although system development is continuing at a rapid pace, this development has remained largely unnoticed by the intended users. If the planning community remains unaware, it will not acquire experience of PSS and so demand will not develop, which will result in insufficient payoff for investors in PSS development. Furthermore, the process of improving existing tools by practice will remain slow. This means that in terms of product life cycle, the product will not get a chance to mature and to reach the point where its development and proliferation become self-enforcing. Therefore, if no marketing action is taken, it is likely that PSS will not get a good chance to prove their worth as a means for improving spatial planning practice. These conclusions are expected to be at least partially valid for a broader set of computer-based tools, such as PSS in general, GIS, SDSS, integrated assessment models, DSS, and information systems in general.

For anyone who believes in PSS technology and wants to further it, in both a commercial and a noncommercial sense, it is of great importance to start spreading the news about the existence of PSS and their benefits. If planners become aware of the existence of PSS, they might consider undertaking real-world example projects, which will give them experience. Positive experiences could increase users' intentions to start using a PSS structurally in their planning practice. It may be very difficult to convince planners because many have negative attitudes towards computer-based planning tools in general. To have clear arguments to convince potential users, besides the positive results of real-world example projects, thorough research into the potential benefits of PSS for spatial planning is recommended. Such a study could be the next step in an attempt to discern the successes and failures of PSS for spatial planning.

Acknowledgements. The authors kindly thank all respondents for their participation. We also offer our thanks to Kor de Jong and Arie-Pieter van Duijn for their work on the survey, Dick Klosterman and Richard Kingston for opening up their mailing lists, and many others - too numerous to mention here-for their comments and suggestions.

\section{References}

Allen E, Goers R, 2002, "Beyond maps: the next generation of GIS tools", Planning Magazine http://www.crit.com/documents/beyond_maps.pdf

Batty M, 2003, "Planning support systems: technologies that are driving planning", in Planning Support Systems in Practice Eds S Geertman, J Stillwell (Springer, Berlin) pp v-viii

Batty M, Densham, P J, 1996, "Decision support, GIS, and urban planning", http://www.geog.ucl.ac.uk/ $\sim$ pdensham/SDSS/s_t_paper.html

Bishop I, 1998, "Planning Support: hardware and software in search of a system" Computers Environment and Urban Systems $22189-202$

Brail R, Klosterman R (Eds), 2001 Planning Support Systems: Integrating Geographic Information Systems, Models and Visualization Tools (ESRI Press, Redlands, CA) 
Carver S, 2003, "The future of participatory approaches using geographic information: developing a research agenda for the 21st century" URISA Journal (Access and Participatory Approaches I) $1561-71$

Couclelis H, 1989, "Geographically informed planning: requirements for planning relevant GIS", in Proceedings of 36th North American Meeting of Regional Science Association Santa Barbara

Couclelis H, 2003, "Where has the future gone? Rethinking the role of integrated land use models in spatial planning", in Framing Land Use Dynamics: Reviewed Abstracts International Conference, 16-18 April 2003 Faculty of Geographical Sciences, Utrecht University, Utrecht, pp 27-28

Crossland M, Wynne B, Perkins W, 1995, "Spatial decision support systems: an overview of technology and a test of efficacy" Decision Support Systems $14219-235$

Croswell P, 1991, "Obstacles to GIS implementation and guidelines to increase the opportunities for success" URISA Journal 3 43-56

Davis F, 1986 A Technology Acceptance Model for Empirically Testing New End-user Information Systems: Theory and Results PhD Dissertation, Massachusetts Institute of Technology, Cambridge, MA

Davis F, 1989, "Perceived usefulness, perceived ease-of-use, and user acceptance of information technology" MIS Quarterly 13319 - 339

De Man E, 2003, "Cultural and institutional conditions for using geographic information; access and participation" URISA Journal (Access and Participatory Approaches I) 15 29-33

Dijst M, Schot P, De Jong K (Eds), 2003, "Framing land use dynamics, reviewed abstracts”, Faculty of Geographical Sciences, University of Utrecht, Utrecht

Dishaw M, Strong D, 1999, "Extending the technology acceptance model with task-technology fit constructs" Information and Management 36 9-21

Edamura T, Tsuchida T, 1999, "Planning support system for an urban environment improvement project" Environment and Planning B: Planning and Design 26381 - 391

EPA, 2000, "Projecting land-use change: a summary of models for assessing the effects of community growth and change on land-use patterns", EPA/600/R-00/098, US Environmental Protection Agency, Office of Research and Development, Cincinnati, OH

Fishbein M, Ajzen I, 1975 Belief, Attitude, Intention, and Behavior: An Introduction to Theory and Research (Addison-Wesley, Reading, MA)

Frambach R, Schillewaert N, 2002, "Organizational innovation adoption, a multilevel framework of determinants and opportunities for future research" Journal of Business Research 55 163 - 176

Geertman S, Stillwell J, 2003a, "Planning support systems: an inventory of current practice" Computers Environment and Urban Systems 28291 - 310

Geertman S, Stillwell J (Eds), 2003b Planning Support Systems in Practice (Springer, Berlin)

Geertman S, Stillwell J, 2003c, "Planning support systems: an introduction", in Planning Support Systems in Practice Eds S Geertman, J Stillwell (Springer, Berlin) pp 3-23

Geertman S, Stillwell J, 2003d, "Interactive support systems for participatory planning", in Planning Support Systems in Practice Eds S Geertman, J Stillwell (Springer, Berlin) pp 25-44

Guhathakurta S, 2002, "Urban modeling as storytelling: using simulation models as a narrative" Environment and Planning B: Planning and Design 29 895-911

Harris B, 1989, "Beyond geographic information-systems-computers and the planning professional" Journal of the American Planning Association 5585 -90

Harris B, Batty M, 1993, "Locational models, geographical information and planning support systems" Journal of Planning Education and Research 12 84-98

Hisschemöller M, Tol R S J, Vellinga P, 2001, "The relevance of participatory approaches in integrated environmental assessment" Integrated Assessment $257-72$

Hopkins L D, 1999, "Structure of a planning support system for urban development" Environment and Planning B: Planning and Design 26333 - 343

Innes J, Simpson D, 1993, "Implementing GIS for planning" Journal of the American Planning Association $59230-236$

Karahanna E, Straub D, 1999, "The psychological origins of perceived usefulness and ease-of-use" Information and Management $35237-250$

Klosterman R, 1997, "Planning support systems: a new perspective on computer-aided planning" Journal of Planning Education and Research 17 45-54

Klosterman R, 2001, “The what if? Planning Support System”, in Planning Support Systems, Integrating Geographic Information Systems, Models and Visualization Tools Eds R Brail, R Klosterman (ESRI Press, Redlands, CA) pp $263-284$

Klosterman R, Landis J, 1988, "Microcomputers in US planning: past, present and future" Environment and Planning B: Planning and Design $15355-368$ 
Kwartler M, Bernard R, 2001, “CommunityViz: an integrated planning support system”, in Planning Support Systems, Integrating Geographical Information Systems, Models and Visualization Tools Eds R Brail, R Klosterman (ESRI Press, Redlands, CA) pp 285-308

Landis J, 2001, "CUF, CUFII, and CURBA: a family of spatially explicit urban growth and land-use policy simulation models", in Planning Support Systems, Integrating Geographic Information Systems, Models and Visualization Tools Eds R Brail, R Klosterman (ESRI Press, Redlands, CA) pp $157-200$

Masser I, Onsrud H (Eds), 1993 Diffusion and Use of Geographic Information Technologies (Kluwer, Dordrecht)

Mathieson K, 1991, "Predicting user intentions: comparing the technology acceptance model with the theory of planned behaviour" Information Systems Research 2 173-191

Nedovic-Budic Z, 1998, “The impact of GIS technology” Environment and Planning B: Planning and Design $25681-692$

Omer I, 2003, "Web-based planning support system for public participation: an individual perspective", in Proceedings of the 6th AGILE Conference on Geographic Information Science (Presses Polytechniques et Universitaires Romandes, Lausanne) pp 607-612

Rogers E, 1962 Diffusion of Innovations 1st edition (Collier Macmillan, New York)

Rogers E, 2003 Diffusion of Innovations 5th edition (Free Press, New York)

Rotmans J, 1998, “Methods for IA: the challenges and opportunities ahead” Environmental Modeling and Assessment $3155-179$

Schmitz J, Fulk J, 1991, "Organizational colleagues, media richness, and electronic mail-a test of the social-influence model of technology use" Communication Research 18 487-523

Scholten H, Stillwell J (Eds), 1990 Geographical Information Systems for Urban and Regional Planning (Kluwer, Dordrecht)

Sheppard E, Couclelis H, Graham S, Harrington J, Onsrud H, 1999, "Geographies of the information society” International Journal of Geographical Information Science 13797 - 823

Shim J P, Warkentin M, Courtney J F, Power D J, Sharda R, Carlsson C, 2002, "Past, present, and future of decision support technology" Decision Support Systems $33111-126$

Sieber R, 2000, "GIS implementation in the grassroots" URISA Journal 12 15-29

Snyder K, 2004, Placematters.com website, http://www.placematters.us/index2.html

Stillwell J, Geertman S, Openshaw S (Eds), 1999, "Developments in geographical information and planning", in Geographical Information and Planning (Springer, Berlin) pp 3-22

TCDDM-V, 2003, "Tools for community design and decision making, working session V", http://www.placematters.us/TCDDMV/

Thompson R, Higgins C, Howell J, 1991, "Personal computing - toward a conceptual-model of utilization" MIS Quarterly $15125-143$

Uran O, 2002 Spatial Decision Support Systems for Coastal Zone and Water Management PhD thesis, Faculty of Economics and Business Studies, Free University, Amsterdam

Uran O, Janssen R, 2003, "Why are spatial decision support systems not used? Some experiences from the Netherlands" Computers, Environment and Urban Systems 27511 - 526

URISA 2003, "Public participation GIS conference, final program and abstracts", Urban and Regional Information Systems Association, http://www.urisa.org/PPGIS/2003/papers/Final.pdf

Venkatesh V, Davis F, 2000, "A theoretical extension of the technology acceptance model: four longitudinal field studies" Management Science 46 186-204

Voss A, Voss H, Gatalsky P, Oppor L, 2003, "Prototype and further requirements of a real participatory GIS", in Proceedings of the 6th AGILE Conference on Geographic Information Science (Presses Polytechniques et Universitaires Romandes, Lausanne) pp 613-622

Waddell P, 2002, "UrbanSim: modeling urban development for land use transportation and environmental planning" Journal of the American Planning Association 68297 - 314

Wegener M, 2001, "New spatial planning models" Journal of Applied Geography $3224-237$

Wilson B, Sherry L, Dobrovolny J, Batty M, Ryder M, 2002, "Adoption of learning technologies in schools and universities", in Handbook on Information Technologies for Education and Training Eds H Adelsberger, B Collis, J Pawlowski (Springer, New York) pp 293-308

Windrum P, De Berranger P, 2003, "Factors affecting the adoption of intranets and extranets by SMEs: a UK study", http://eaepe.infonomics.nl/index.htm 